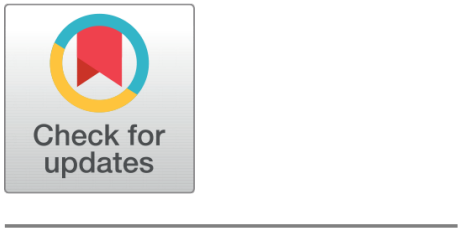

OPEN ACCESS

Received: 19.12 .2020

Accepted: 09.03.2021

Published: 19.03.2021

Citation: Hossen MT, Islam T, Mahee El, Reza ZT, Rahman M, Mahmud MS (2021) A comprehensive study on Physico-Mechanical characteristics of Okra fibre (Abelmoschus esculentus) for textile applications. Indian Journal of Science and Technology 14(9): 765-775. https://d oi.org/10.17485/IJST/v14i9.2268

* Corresponding author.

mth.te@just.edu.bd

Funding: None

Competing Interests: None

Copyright: @ 2021 Hossen et al. This is an open access article distributed under the terms of the Creative Commons Attribution License, which permits unrestricted use, distribution, and reproduction in any medium, provided the original author and source are credited.

Published By Indian Society for Education and Environment (iSee)

ISSN

Print: 0974-6846

Electronic: 0974-5645

\section{A comprehensive study on Physico-Mechanical characteristics of Okra fibre (Abelmoschus esculentus) for textile applications}

\author{
Md. Tanvir Hossen ${ }^{1 *}$, Tarikul Islam ${ }^{1}$, Emdadul Islam Mahee ${ }^{2}$, \\ Zarin Tasnim Reza ${ }^{3}$, Mahbubur Rahman ${ }^{4}$, Md. Sultan Mahmud ${ }^{5}$ \\ 1 Department of Textile Engineering, Jashore University of Science and Technology, Jashore- \\ 7408, Bangladesh \\ 2 Assistant Manager, Technical and Marketing, Texxet International, Dhaka, Bangladesh \\ 3 Department of Fashion Design, BGMEA University of Fashion \& Technology, Bangladesh \\ 4 Department of Textile Engineering, Mawlana Bhashani Science and Technology University, \\ Tangail-1992, Bangladesh \\ 5 Department of Yarn Engineering, Bangladesh University of Textiles, Dhaka, Bangladesh
}

\begin{abstract}
Objectives: The objectives of this research is to investigate the physicomechanical characteristics of okra bast fibres (OBF) as well as to go through all the process to make this okra fibre as one of the commercial cellulosic fibres which can be used in different textile applications such as reinforcements in polymer matrix composites, carpets, materials used for absorbing oils and liquids, packaging industries, basic textiles products, coarse decorative textile products, Geo-textiles etc. all over the world. Methodology: In this work, OBFs are characterized by using Fourier transform infrared spectroscopy (FTIR), Breaking strength and breaking extension test, linear density analysis, Microscopic view and Scanning electron microscopy (SEM) analysis, and the crystallinity is measured by X-Ray Diffraction (XRD) data. Findings: XRD data indicates that the amorphous region is far greater than the crystalline region in OBFs, SEM analysis displays the technical fibres are overlapped and cemented by non-cellulosic compounds. These test results show a great similarity to other bast fibres properties mainly physical, mechanical, microstructural (crosssectional and longitudinal view) properties.
\end{abstract}

Keywords: Okra bast fibre (OBF); SEM; FTIR; XRD; Breaking strength and breaking extension; Linear density

\section{Introduction}

Natural fibres contribute a lot of distinct advantages over other traditional manmade fibres and fillers with its limitless application areas ${ }^{(1)}$. The necessity of finding ecologically friendly alternatives to traditional synthetic fibres for instance glass fibres to be used as reinforcement in polymer matrix composites and other textile applications 
have attracted a rising interest in natural cellulosic fibres recently ${ }^{(2)}$. The thermal stability of such composites along with less common natural fibre composites and other textile applications will also need to be investigated for specific works on the practical use ${ }^{(3)}$. In this regard, this work provides a comprehensive overview of a very less common but promising natural cellulosic fibre known as Okra (Abelmoschus esculentus) bast fibre. An economically significant vegetable crop okra belonging to the Malvaceae family is grown in tropical and subtropical regions of the world ${ }^{(4)}$ and okra technical fibres are extracted from the skin or bast surrounding the stem of their respective plant ${ }^{(5)}$. So, it is said that the okra plant consists of core and bast fibre $^{(6)}$. Generally, Okra has been used as a nutritive vegetable and pharmaceutical material for humans as well as feedstuffs for livestock for a long time ${ }^{(7-9)}$ and the okra plants are agricultural waste products after collecting vegetables. As there is very limited use of okra as a textile fibre, Bangladesh might have a great prospect in cultivating, extraction and go through all the process to make this $\mathrm{OBF}$ as one of the commercial cellulosic fibres in this favour and it could be applied as a textile fibre and also as a reinforcement material for polymeric composites as a substitute for other man-made fibre ${ }^{(10)}$. In this case, it is required to understand their microstructure and mechanical properties for their use as textile fibres and as potential reinforcement in polymer composites ${ }^{(11-14)}$. Owing to growing environmental awareness, composites manufactured from lingo-cellulosic fibres as reinforcing material are discovering gradually ${ }^{(15-18)}$. The maximum length of the extracted fibres is more than $60 \mathrm{~cm}^{(19)}$. The literature on elevated implementations of okra fibres barely exists. Those studies mainly emphasized on the use of this fibre as a reinforcement in composites ignoring the potential uses in producing basic textile products.

In this work, it has been focused on finding out the morphological structure (longitudinal profile, cross-sectional view) by SEM analysis, chemical bonds and functional groups in the fibre by FTIR, breaking the tension and tensile properties by Single Fibre Strength and elongation tester and cellulosic structure of okra fibre by XRD test. The test results were analyzed by different procedures. This crucially relevant sounder study which can yield some effective insights not only in the fruitfulness of fibre extraction but also in preparation for using the okra fibres as a raw material of higher-profile applications such as producing cloth for wrapping bales of raw cotton, to manufacture coarse cloth and sacks, and producing carpets, area rugs, ropes, twine, hessian cloth etc. along with the application as reinforcements in the polymer matrix composites.

\section{Materials and Methods}

\subsection{Materials}

In this work, okra bast fibre (OBF) is used which was collected from Tangail district of Bangladesh. The fibres were extracted by retting and manual extraction method ${ }^{(20)}$. At first, about 2 months old fresh okra plants having around 2 to $2.2 \mathrm{~m}$ height were collected and the central part of the stems was removed. Then the stems were kept underwater to allow microbial degradation and the stems degraded sufficiently within around 18-22 days to allow fibre extraction ${ }^{(21)}$. Fibres were taken off from single okra plants. This was a time-consuming process but delivered a good quality of fibres. The fibre was removed from the water as soon as possible when the regular inspection of the stems showed that the bark could be eliminated simply from the rest of the stem. The fibres were isolated from the degraded stems by washing several times with clean water and then dried in the open air in the form of rope and the moisture-proof container is used to keep these sample fibres afterwards. OBFs show a multilateral shape and thickness of fibre varies along the length.

\subsection{Methods}

SEM was executed to investigate fibre's microstructure and morphology. Morphology of single okra fibre was done using JEOL JSM-7100F Scanning Electron Microscope with Field-Emission source ${ }^{(22)}$. The SEM analysis was done in a longitudinal direction, on cross-section (normal), on cross-section (after fracture). The SEM images were magnified 200\%, 400\%, 600\%, $800 \%$ and $1000 \%$. Among those images, $200 \%$ and $600 \%$ magnified images were clear enough to observe. No coating or special treatment was done on OBF for the analysis. The surface structure of the textile fibre is very important because it determines the cohesiveness, adhesiveness, dye penetration etc. X-Ray Diffraction test is done to find out the orientation of the polymeric chain such as crystalline, microcrystalline or amorphous present in the okra fibre. This X-ray diffraction measurement was performed using an X-ray diffractometer. A copper K- $\alpha$ X-ray source with $40 \mathrm{kV}$ voltage and $40 \mathrm{~mA}$ power was used to record the diffraction patterns. The intensity as a function of the scattering angle is evaluated by the MS Excel spreadsheet tool after getting the diffraction patterns. The wavelength of the electron beam was Lambda, $\wedge=1.54063$. The filter used here was a Solidstate detector. FTIR is used to analyze the chemical bonds and functional groups of the components of OBF. In this work, FTIR was done on raw OBF without any modification of fibre. The chemical bonds and functional groups of the fibre components determine the chemical reactions of the textile fibre in subsequent processes and during end uses. One of the most important characteristics of textile fibre is the strength of the fibre. So, the tensile strength of okra fibre was determined by ASTM D1578-93 
method $^{(23)}$. The sample was in bundle form and three sets of fibers in bundle form were tested. The cross-sectional shape of OBF was observed by using a projection microscope. The determination of linear density of okra fibre was done using gravimetric analysis. For this analysis, first of all, the single okra fibres were separated from the mesh structure manually (hand splitting). Then the individual single fibre's length was measured manually by a scale and weighed individually. This procedure was done for 18 samples (single fibre). After that the linear density of the individual fibre was determined and at the end, the mean value and coefficient of variation of linear density were also calculated.

\section{Results and Discussion}

\subsection{Analysis of tensile strength}

Table 1. Tensile strength of okra fibre

\begin{tabular}{ccc}
\hline Specimen No. & Tensile strength $(\mathrm{N} / \mathrm{m} 2)$ & Extension $(\%)$ \\
\hline 1 & 4.46 & 2.57 \\
2 & 5.18 & 2.22 \\
3 & 5.31 & 1.77 \\
4 & 5.76 & 2.55 \\
5 & 5.44 & 1.83 \\
Mean & 5.23 & 2.19 \\
\hline
\end{tabular}

The tensile strength of OBF is lower at the cut portions ${ }^{(24)}$ and the top compared to the middle because the middle portion contains the higher cellulose content. The breaking strength of the OBF was lower at the cut portion and top. Whereas the center portion showed a better breaking strength the reason for this may be due to the high content of cellulose. Another important issue is that the top and cutting portions fibres were immature and over mature respectively whereas middle portions were matured. With span length, the tensile strength and strain to failure for all portions lessened. This is due to the lesser test span length being considerably influenced by fibre properties and machine parameters ${ }^{(25)}$. Tenacity is the term normally used for expressing fibre strength which consists of breaking force and linear density of fibre. 5 tests have been done for strength measurement of okra fibres samples (Table 1) taken from the middle portion.

\subsection{Analysis of breaking strength and breaking extension}

From the Figure 1, it shows that the fibre is very much rigid because there is low elongation through applied force is high. This low extension rate due to for the presence of lignin on the surface of fibres which is a cemented material and the amount of lignin affects the breaking strength and elongation of single fibres considerably. Breaking strength and elongation of single fibres reduce with the increasing of the amount of lignin ${ }^{(26)}$.

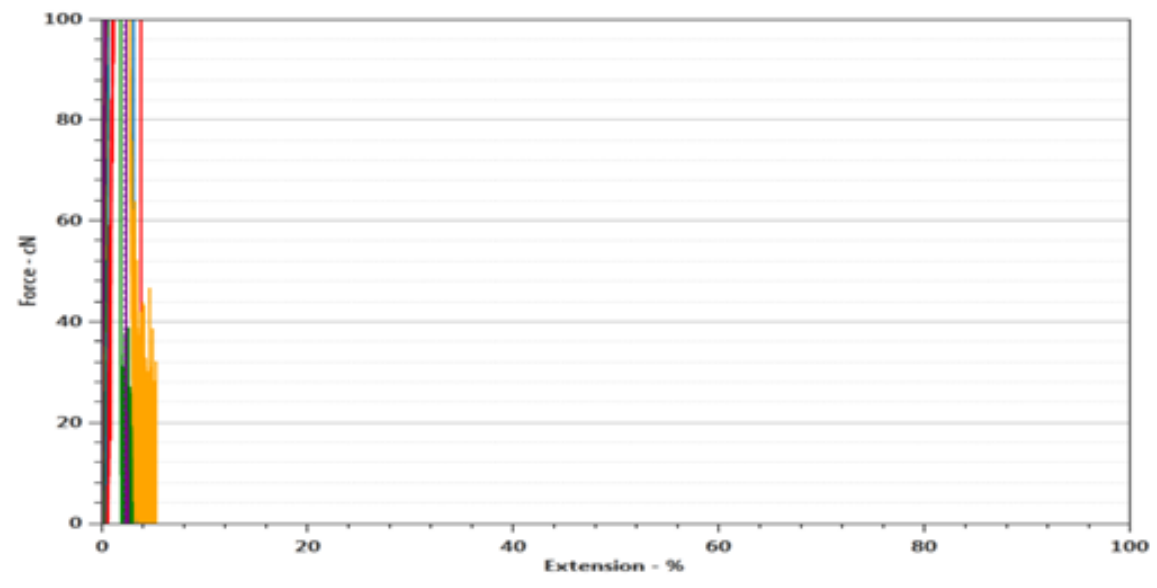

Fig 1. The force-elongation curve of okra fibre 


\subsection{Analysis of linear density}

The linear density of okra fibre was calculated by gravimetric analysis. At first, the single fibres from the meshy structure were separated by hand splitting. So, the thickness of the single fibres was not much even or uniform. Then the length and weight of 18 samples fibres were evaluated.

Table 2. Linear density of okra fibre

\begin{tabular}{|c|c|c|c|}
\hline Sample No. & Length $(\mathrm{mm})$ & Weight(mg) & Tex (individual fibre) \\
\hline 1 & 85 & 0.40 & 4.71 \\
\hline 2 & 81 & 0.37 & 4.57 \\
\hline 3 & 92 & 0.37 & 4.02 \\
\hline 4 & 84 & 0.36 & 4.64 \\
\hline 5 & 115 & 0.41 & 3.57 \\
\hline 6 & 108 & 0.49 & 4.54 \\
\hline 7 & 117 & 0.52 & 4.44 \\
\hline 8 & 112 & 0.44 & 3.93 \\
\hline 9 & 98 & 0.45 & 4.59 \\
\hline 10 & 80 & 0.45 & 5.63 \\
\hline 11 & 107 & 0.39 & 3.64 \\
\hline 12 & 75 & 0.34 & 4.53 \\
\hline 13 & 90 & 0.39 & 4.33 \\
\hline 14 & 68 & 0.32 & 4.71 \\
\hline 15 & 92 & 0.54 & 5.87 \\
\hline 16 & 79 & 0.33 & 4.17 \\
\hline 17 & 93 & 0.33 & 3.55 \\
\hline 18 & 122 & 0.56 & 4.59 \\
\hline \multicolumn{3}{|c|}{ Mean value of linear density (Tex) } & 4.446 \\
\hline \multicolumn{3}{|c|}{ Coefficient of variation (CV \%) } & $13.84 \%$. \\
\hline
\end{tabular}

From the Table 2, it shows the higher CV\% of linear density of okra fibre and it maybe happened to the uneven hand splitting of single okra fibre from their meshy structure. This separation process is very hard and complicated as these single fibres orientated in a very complex mesh structure which is very difficult to break without damaging the fibres.

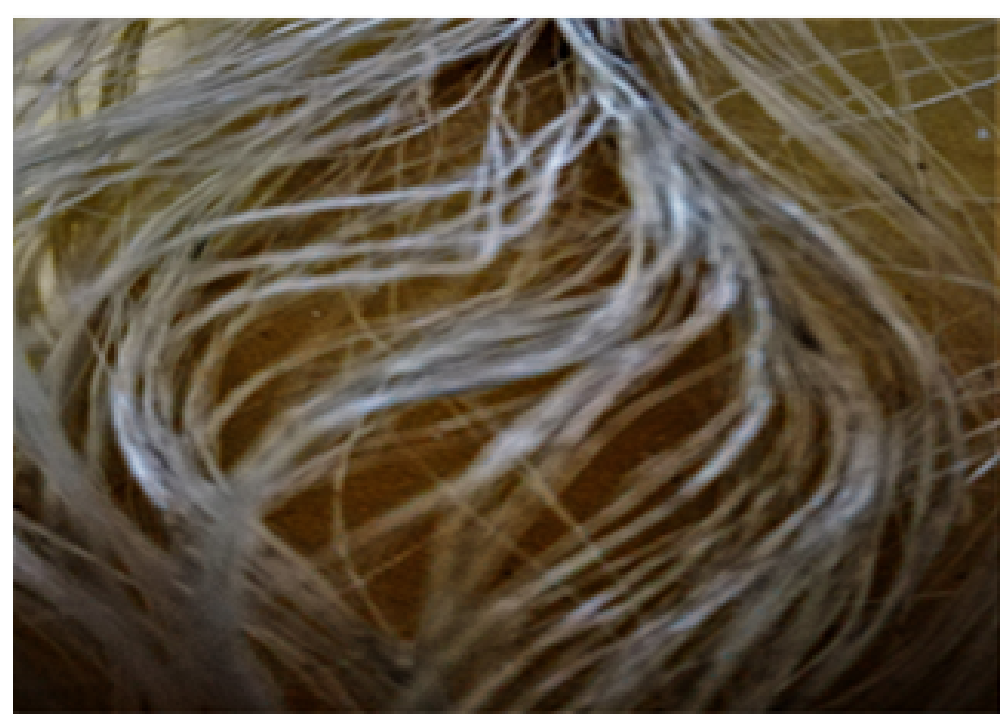

Fig 2. Meshy structure of Okra fibre 


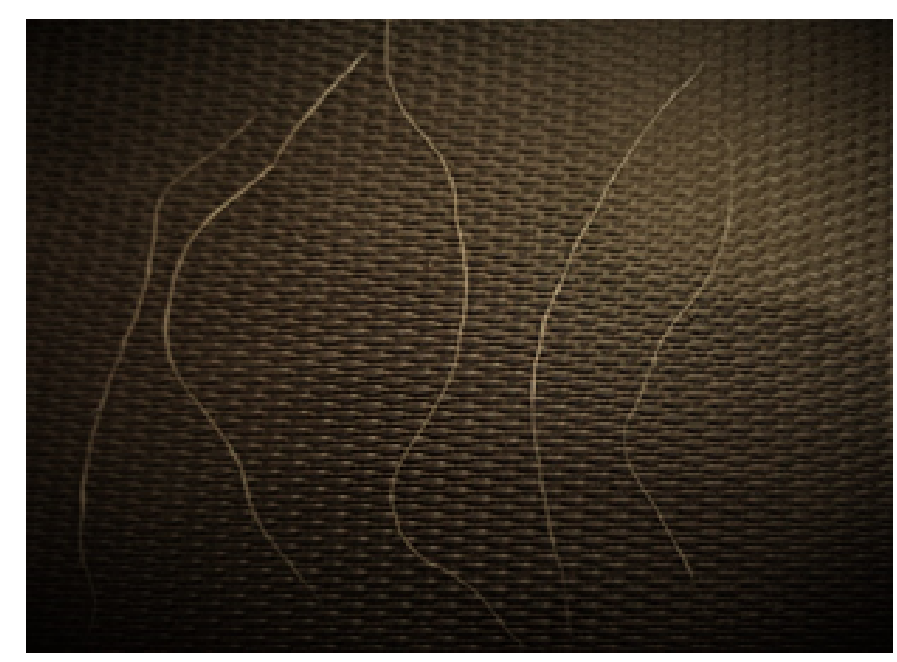

Fig 3. Single Okra fibre

\subsection{Microscopic view of okra fibre}
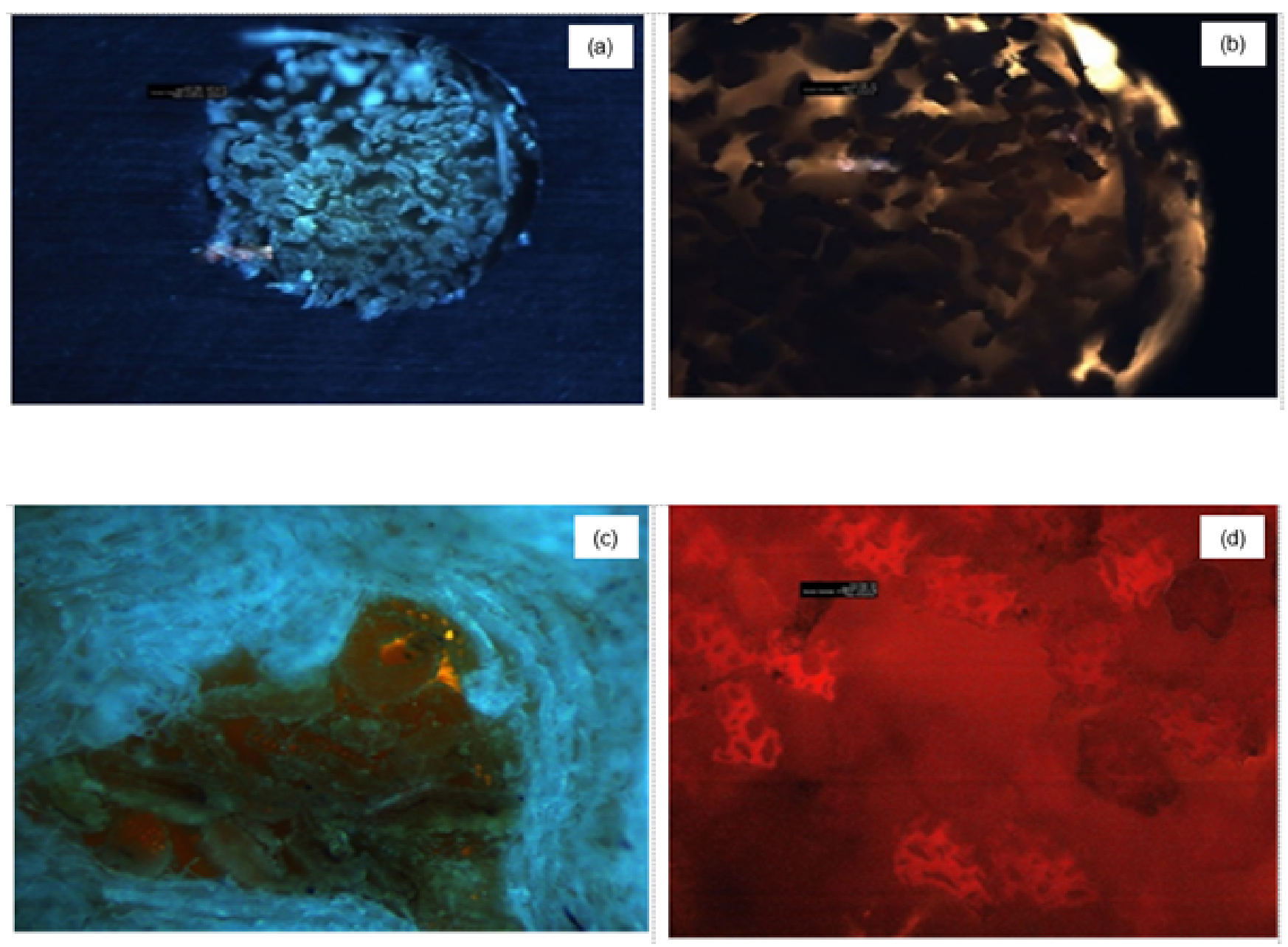

Fig 4. (a) 50 times magnified view (b) 100 times magnified view (c) 100 times magnified view through the cork (d) 400 times magnified view 
From Figure 4, it shows that the cross-sectional shape of the okra fibre is observed by using a projection microscope. The cross-section of the okra fibre tends to flat to polygonal shape and the fibre thickness varies a lot. Usually, an okra fibre's structure contains several elementary fibres overlapped along the fibre length and glued firmly together by non-cellulosic compounds and pectin that contribute strongly to the bundle as a whole. These elementary fibres are referred to as ultimate fibres or cells. However, the strength of the elementary cell is considerably higher than that of the bundle structure. The term "Middle lamella" is considered for the region at the interface of two cells. Technical fibres or single fibres are the common terminologies used for the bundles of elementary fibres ${ }^{(27)}$.

\subsection{SEM analysis}
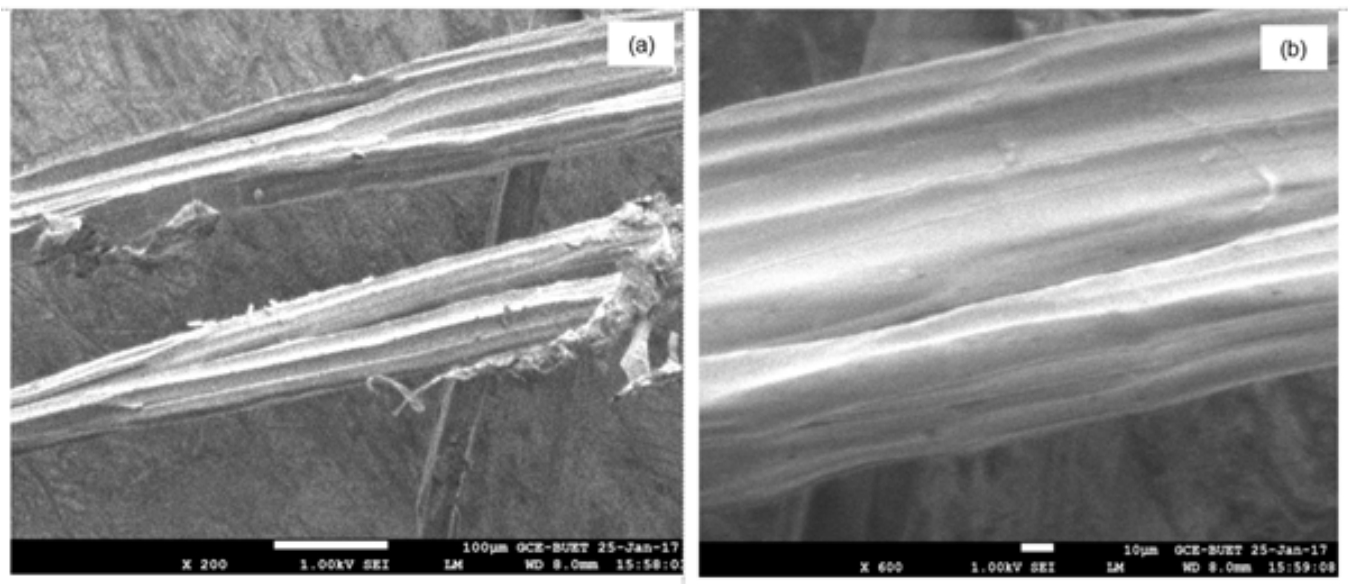

Fig 5. (a), (b) SEM images of Okra fibre, 200 and 600 times respectively (longitudinal view)

From Figure 5, it is observed that the overlapping of the cells appears in a longitudinal view of the fibres. Moreover, it shows the presence of some contaminations on the surface of the okra fibre and also the fibres are covered in non-cellulosic compounds.
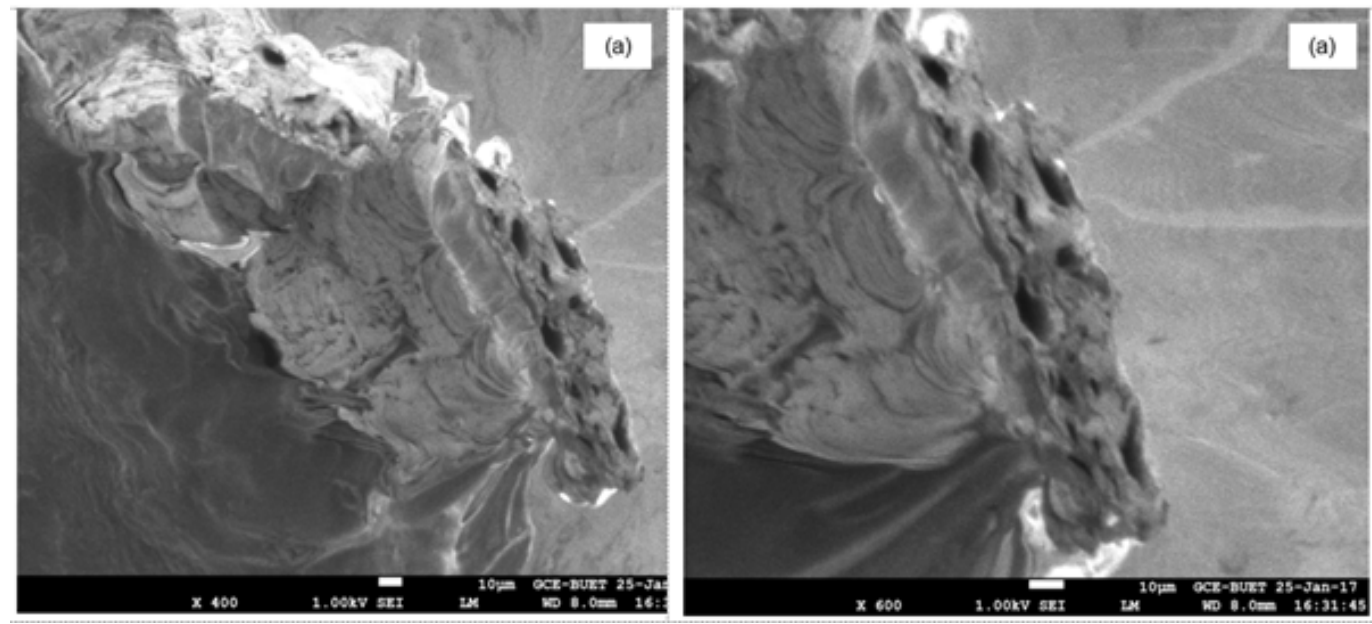

Fig 6. (a), (b) SEM images of okra fibre (cross-section)

From Figure 6, the cross-section of okra fibre indications a polygonal shape. This shape differs particularly from irregular profile to reasonably circular. Besides each ultimate cell is unevenly polygonal in shape having a central hole or lumen. This significant difference between the diameter values of the single fibre and lumen and their rough shape intensely affect mechanical and dimensional properties of $\mathrm{OBFs}^{(28)}$.

From Figure 7, it represents that the fracture occurs almost evenly. With the absence of substantial fibril splitting OBFs displayed a brittle behaviour. In the outer portion of the bundle, some fibre pull-out is detected whilst at the centre pull-out is 

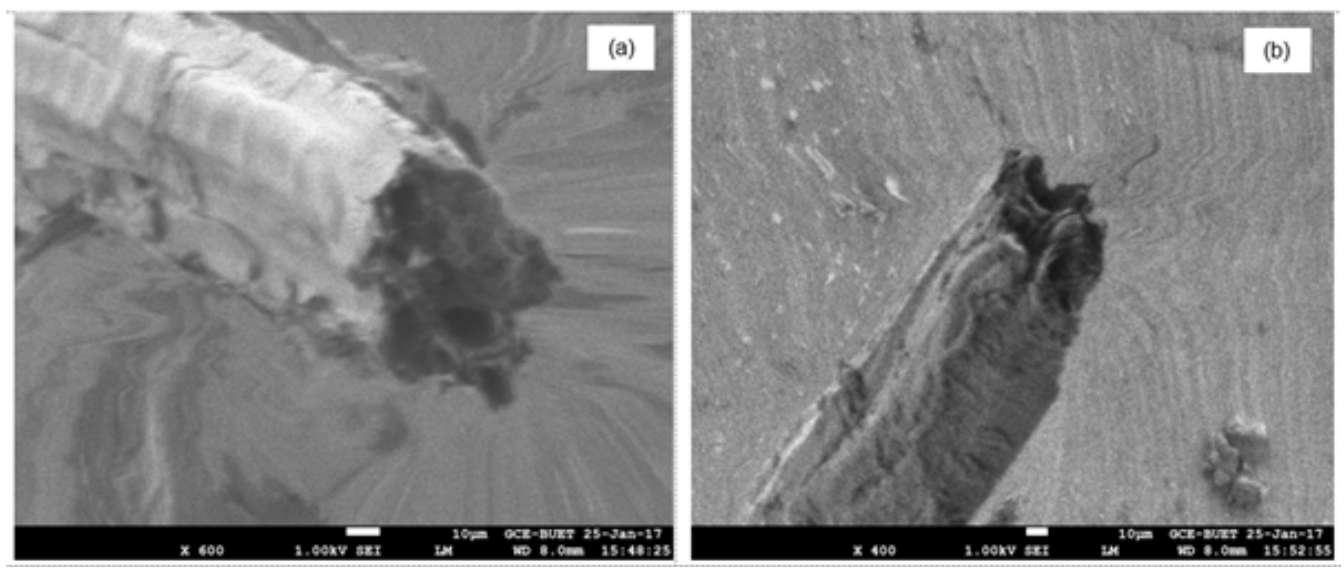

Fig 7. (a), (b) SEM images of fractured okra fibre (cross-section)

not visible that much which directs the presence of adequate binding material (commonly lignin). Additionally, all fibre cells have not fractured at the equal stress level probably due to cell wall defects existing along the fibre length which can generate stress intensities leading to ultimate failure ${ }^{(27)}$. The SEM images of okra fibres are very much similar to the SEM images of other bast fibres. The ultimate fibres are a cellulosic wall with lignin and pectin are also seen in Jute fibre ${ }^{(28)}$. Both okra fibre and jute fibres are cemented with a lot of ultimate fibres.

\subsection{XRD analysis}

An X-ray diffractometer with reflection mode was utilized for XRD measurements.

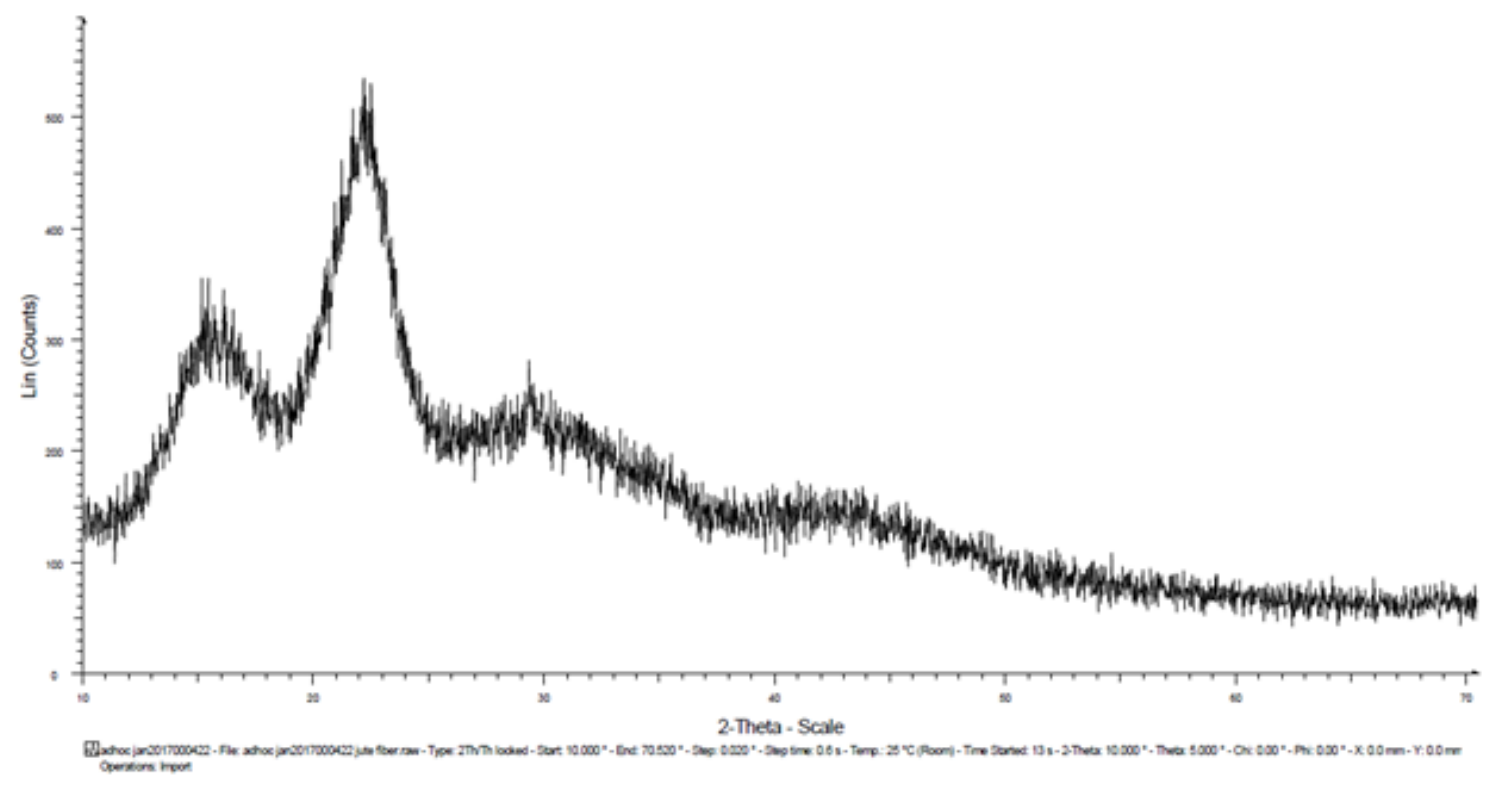

Fig 8. X-raypattern of okra fibre

This pattern (Figure 8) shows the peaks of the diffraction recorded and by using a pattern with the standard the crystalline or amorphous regions are evaluated. Comparison between the actual pattern (Figure 8) and the patter with standard (Figure 9), it shows that the peaks resemble with cellulose I alpha. The formula of the compound evaluated from the pattern resembles 


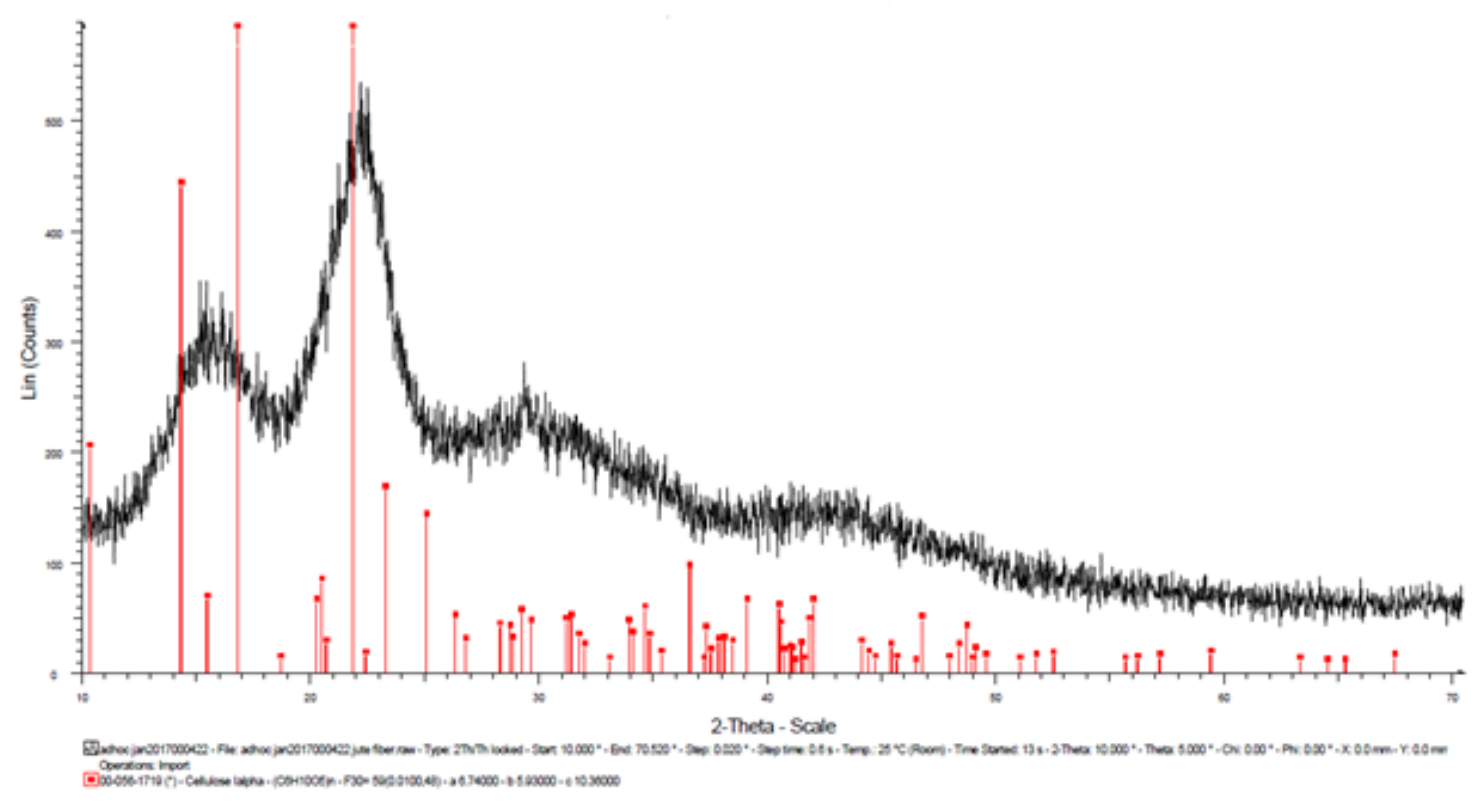

Fig 9. Pattern with the standard of okra fibre

$\left(\mathrm{C}_{6} \mathrm{H}_{10} \mathrm{O}_{5}\right)_{n}$. The pattern resembles mostly $\alpha$-cellulose. On the other hand, the amorphous polymer shows weak medium peaks like structure. By comparison with the basic patterns, it is noticed that examined sample of okra fibre pattern matches with the amorphous pattern. So, the okra fibre XRD pattern shows amorphous regions all over the pattern. As a result, okra fibre is amorphous polymers. As it is known that cellulosic compounds show amorphous characteristics in XRD pattern and the examined sample is a cellulosic compound. So, according to the tests and evaluations, okra fibre is an amorphous polymer. The amorphous region is far greater than the crystalline region in okra fibre.

From the basic crystal structure of okra fibre from the XRD pattern, it observed that there are seven basic patterns of the crystal. These are Triclinic, Monoclinic, Orthorhombic, Tetragonal, Hexagonal, Rhombohedral and Cubic. These seven crystal structure formations maintain some condition in the XRD pattern. These conditions are mainly associated with the miller indices parameters (hkl). From the parameters the value of a, b, $\mathrm{c}$ and the angles $(\alpha, \beta, \gamma)$ between them are evaluated. Relations between the value and angles of $a, b, c$ are responsible for the conditions which determine the crystal structure. The conditions are given below:

Table 3. Conditions of crystal structure

\begin{tabular}{cc}
\hline Structure & Conditions \\
\hline Triclinic & No restrictions \\
Monoclinic & $\alpha=\gamma=90^{0}$ \\
Orthorhombic & $\alpha=\beta=\gamma=90^{0}$ \\
Tetragonal & $\alpha=\beta=\gamma=90^{0}, \mathrm{a}=\mathrm{b}$ \\
Hexagonal & $\alpha=\beta=90^{0}, \gamma=120^{0}, \mathrm{a}=\mathrm{b}$ \\
Rhombohedral & $\alpha=\beta=\gamma<120^{0}, \mathrm{a}=\mathrm{b}=\mathrm{c}$ \\
Cubic & $\alpha=\beta=\gamma=90^{0}, \mathrm{a}=\mathrm{b}=\mathrm{c}$ \\
\hline
\end{tabular}


Table 4. Evaluatedvalue of okra fibre

\begin{tabular}{cc}
\hline Parameters & Value \\
\hline $\mathrm{a}$ & $6.7400^{0}$ \\
$\mathrm{~b}$ & $5.9300^{\circ}$ \\
$\mathrm{c}$ & $10.3600^{\circ}$ \\
$\alpha$ & $117.00^{0}$ \\
$\beta$ & $113.00^{0}$ \\
$\gamma$ & $81.00^{0}$ \\
\hline
\end{tabular}

From the evaluated data (Tables 3 and 4 ), it shows that the value and angles of the parameters maintain no conditions or restrictions. The crystal structure of okra fibre is Triclinic. The molecular weight and the volume are also evaluated from the XRD pattern. From the analysis, the molecular weight is 162.14 and the volume (CD) is 339.50 . So, the total evaluation from the XRD pattern is okra fibre is a cellulosic compound whose formula is $\left(\mathrm{C}_{6} \mathrm{H}_{10} \mathrm{O}_{5}\right)_{n}$, okra fibre is an amorphous polymer and the crystal structure of okra fibre is triclinic.

\subsection{FTIR analysis}

The chemical structure of the components of okra fibre from FTIR analysis, it is noticed that the main absorbance peaks of interest have been identified here. FTIR spectrum of the okra shows absorption bands of a chemical group's characteristic of lignocellulosic fibre compound. These are cellulose, hemicellulose and lignin. These components are primarily made of alkenes, aromatic groups and several functional groups containing oxygen (ester, ketone and alcohol).

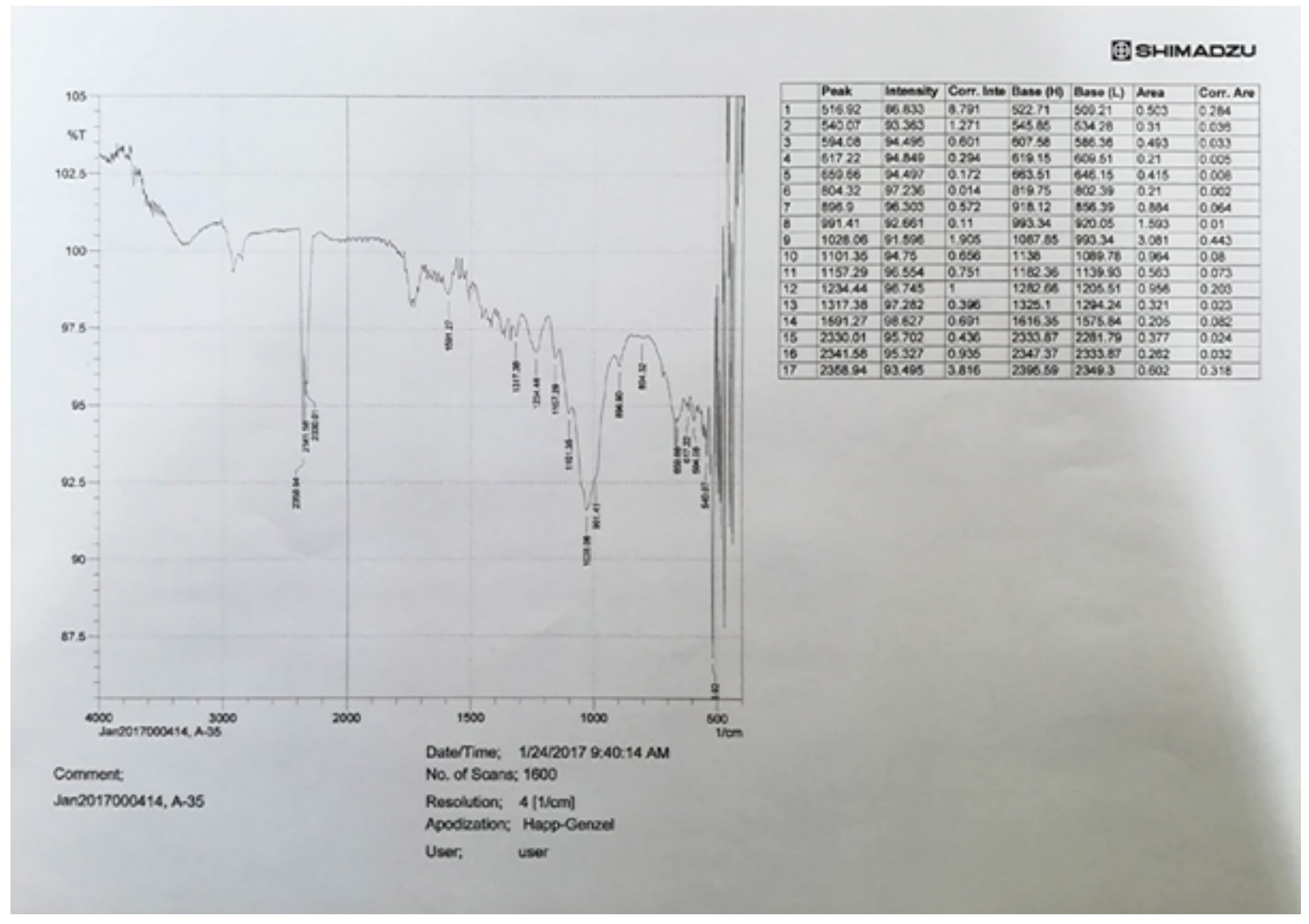

Fig 10. FTIR spectrum of okra fibre 
From Figure 10, It shows that the peaks at $2800-2900 \mathrm{~cm}^{-1}$ are the distinctive band for $\mathrm{C}-\mathrm{H}$ stretching vibration from $\mathrm{CH}$ and $\mathrm{CH}_{2}$ in cellulose and hemicellulose components whilst the absorbance at $2330.01 \mathrm{~cm}^{-1}, 2341.58 \mathrm{~cm}^{-1}, 2358.94 \mathrm{~cm}^{-1} \mathrm{goes}^{-1}$ to the carbonyl $\mathrm{C}=\mathrm{O}$ stretching vibration of carboxylic acid linkage in lignin or ester group in hemicellulose. These carboxylic groups may also be existing in the fibre as traces of fatty acids in oils. The slight shoulder at $1600-1700 \mathrm{~cm}^{-1}$ maybe for the existence of $\mathrm{H}_{2} \mathrm{O}$ in the fibres. A tiny peak at $1591.38 \mathrm{~cm}^{1}$ is for the $\mathrm{C}=\mathrm{O}$ stretching of the aromatic ring of the lignin. The absorbance peaks at $1101.35 \mathrm{~cm}^{-1}$ and $1234.44 \mathrm{~cm}^{1}$ attributes to $\mathrm{C}-\mathrm{O}$ stretching vibration of the acetyl group in lignin and hemicellulose respectively. The peaks at $804.32 \mathrm{~cm}^{-1}$ and $991.41 \mathrm{~cm}^{-1}$ are attributed to the presence of the $\mathrm{C}=\mathrm{C}$ symmetric bending of cellulose. The peak observed at $1317.38 \mathrm{~cm}^{-1}$ in the spectrum indicates the bending vibration of $\mathrm{C}-\mathrm{H}$ and $\mathrm{C}-\mathrm{O}$ of the aromatic ring in polysaccharides. The absorbance peak at $1157.29 \mathrm{~cm}^{-1}$ is for the anti-symmetrical deformation of C-O-C band. The significant absorption peak at $1028.06 \mathrm{~cm}^{-1}$ is ascribed to the $\mathrm{CO}$ and $\mathrm{O}-\mathrm{H}$ stretching vibration for polysaccharide in cellulose. The peak observed at $896.90 \mathrm{~cm}^{-1}$ is ascribed to the existence of $\beta$-glycosidic linkages between the mono-saccharides. Besides, the absorbance at $594.08 \mathrm{~cm}^{-1}$ corresponds to the $\mathrm{C}-\mathrm{OH}$ bending. The peaks at $516 \mathrm{~cm}-1$ and $540.7 \mathrm{~cm}-1$ are attributed to the presence of the C-I stretching halo compound and peaks at $617.22 \mathrm{~cm}-1$ and $659.65 \mathrm{~cm}-1$ are ascribed to the presence of the $\mathrm{C}-\mathrm{Br}$ stretching halo compound.

\section{Conclusion}

All the investigations were done for the characterization of okra fibre using projection microscopy, SEM, XRD, FTIR, tensile strength and linear density analysis. By studying the Physico-Mechanical Characteristics, it is comprehended that okra fibre contains the capability to be used as potential textile fibres and can be spun into yarn and can be converted into cloth mainly coarse cloth, carpets, area rugs, sacks, insulation, animal bedding, decorative hessian cloth etc. together with applications as reinforcements in polymer matrix composites and as cellulosic raw materials in cellulose-based industries owing to containing high cellulose quantity. Okra fibre might have a great chance to be used as commercial bast fibre and might be an alternative to other bast fibres such as kenaf, sisal, jute etc. to meet the growing demand of biodegradable natural fibres.

\section{Conflict of Interest}

Authors have declared that they have no conflict of interest regarding publishing the article.

\section{Funding}

None.

\section{References}

1) Ebele CC, Okonkwo, Ugochukwu C, Bright, Oweziem U, Chidiebere M. Effects of Chemical Treatment on Impact Property of Coir Fibre Reinforced Polyester (CFRP) Composites. American Journal of Engineering. 2015;2(5):125-130.

2) Omrani E, Menezes PL, Rohatgi PK. State of the art on tribological behavior of polymer matrix composites reinforced with natural fibers in the green materials world. Engineering Science and Technology, an International Journal. 2016;19(2):717-736. Available from: https://dx.doi.org/10.1016/j.jestch. 2015.10.007.

3) Onyedum O, Aduloju SC, Sheidu, Sumaila O, Metu, Chidiebere S, et al. Comparative Mechanical Analysis of Okra Fibre and Banana Fibre Composite Used in Manufacturing Automotive Car Bumpers. American Journal of Engineering. 2015;2(5):193-199.

4) Binalfew T, Alemu, Yosef. Characterization of Okra (Abelmoschus esculentus (L.) Moench) Germplasms Collected from Western Ethiopia. International Journal of Research in Agriculture and Forestry. 2016;3(2):11-17.

5) Yllmaz ND, Konak S, Yllmaz K, Kartal AA, Kayahan E. Characterization, modification and use of biomass: okra fibers. Bioinspired, Biomimetic and Nanobiomaterials. 2016;5:85-95. Available from: https://dx.doi.org/10.1680/jbibn.15.00014.

6) Jahan MS, Alam D, Rahman MM, Quaiyyum MA. Isolation and characterization of lignin from okra (Abelmoschus esculentus) fibre and stick. Bangladesh Journal of Scientific and Industrial Research. 2015;50(4):257-262. Available from: https://dx.doi.org/10.3329/bjsir.v50i4.25834.

7) Khan GMA, Shaheruzzaman M, Rahman MH, Razzaque SMA, Islam MS, Alam MS. Surface modification of okra bast fiber and its physico-chemical characteristics. Fibers and Polymers. 2009;10(1):65-70. Available from: https://dx.doi.org/10.1007/s12221-009-0065-1.

8) Khan GMA, Yilmaz ND, Yilmaz K. OBFs: Potential material for green biocomposites. In: Green biocomposites. Springer, Cham. 2007;p. $261-284$.

9) Yilmaz ND. Agro-residual fibres as potential reinforcement elements for biocomposites. Lignocellulosic Polymer Composites: Processing, Characterization, and Properties. 2014;p. 233-233.

10) Rosa IMD, Kenny JM, Puglia D, Santulli C, Sarasini F. Morphological, thermal and mechanical characterization of okra (Abelmoschus esculentus) fibres as potential reinforcement in polymer composites. Composites Science and Technology. 2010;70(1):116-122. Available from: https://dx.doi.org/10.1016/j. compscitech.2009.09.013.

11) Srinivasababu N, Rao M, Murail K, and JSK. Tensile properties characterization of okra woven fibre reinforced polyester composites. International Journal of Engineering. 2009;3(4):403-412. Available from: https://www.cscjournals.org/library/manuscriptinfo.php?mc=IJE-103.

12) Potluri R, Paul KJ, kalam SA, Prasanthi P. Mechanical Properties Characterization of Okra Fiber Based Green Composites \& Hybrid Laminates. Materials Today: Proceedings. 2017;4(2):2893-2902. Available from: https://dx.doi.org/10.1016/j.matpr.2017.02.170. 
13) Rahman, Masudur ANM, Shah A, Amin KR, Ershad KM, Nazmul HS. Fabrication, Mechanical Characterization and Interfacial Properties of Okra Fibre Reinforced Polypropylene Composites. 2018.

14) Rao K, Venkateswara. .

15) Gowda TM, Naidu ACB, Chhaya R. Some mechanical properties of untreated jute fabric-reinforced polyester composites. Composites Part A: Applied Science and Manufacturing. 1999;30(3):277-284. Available from: https://dx.doi.org/10.1016/s1359-835x(98)00157-2.

16) Hassan MM, Islam MR, Khan MA. Surface Modification of Cellulose by Radiation Pretreatments with Organo-Silicone Monomer. Polymer-Plastics Technology and Engineering. 2005;44(5):833-846. Available from: https://dx.doi.org/10.1081/pte-200060836.

17) Idicula $M$, Thomas $S$. Effect of fibre loading and fibre ratio on the mechanical properties of intimately mixed banana/sisal hybrid fibre reinforced composites. In: 5th Global Wood and Natural Fibre Composites Symposium. Kassel, Germany. 2004.

18) Islam T, Khan RA, Khan MA, Rahman MA, Fernandez-Lahore M, Huque QMI, et al. Physico-Mechanical and Degradation Properties of GammaIrradiated Biocomposites of Jute Fabric-Reinforced Poly(caprolactone). Polymer-Plastics Technology and Engineering. 2009;48(11):1198-1205. Available from: https://dx.doi.org/10.1080/03602550903149169.

19) Srinivasababu N. An Overview of Okra Fibre Reinforced Polymer Composites. IOP Conference Series: Materials Science and Engineering. 2015;83. Available from: https://dx.doi.org/10.1088/1757-899x/83/1/012003.

20) Rahman MMM. 35-A Study By Scanning Electron Microscopy of The Progressive Delignification of Jute Fibres. The Journal of The Textile Institute. 1978;69(9):287-293. Available from: https://dx.doi.org/10.1080/00405007808631457.

21) Acha BA, Marcovich NE, Reboredo MM. Physical and mechanical characterization of jute fabric composites. Journal of Applied Polymer Science. 2005;98(2):639-650. Available from: https://dx.doi.org/10.1002/app.22083.

22) Khan MAS, Arifuzzaman GM. Chemical Analysis of Okra Bast Fibre (Abelmoschus esculentus) and Its Physico-chemical properties. Journal of Textile and Apparel. 2007;5(4):1-9.

23) Shahinur S, Hasan M, Ahsan Q, Saha DK, Islam MS. Characterization on the Properties of Jute Fiber at Different Portions. International Journal of Polymer Science. 2015;2015:1-6. Available from: https://dx.doi.org/10.1155/2015/262348.

24) Stawski D, Çalişkan E. Nazire Deniz Yilmaz, and Izabella Krucińska. Thermal and Mechanical Characteristics of Okra (Abelmoschus Esculentus) Fibres Obtained Via Water- and Dew-Retting. Applied Sciences; 10.

25) Fortunati E, Puglia D, Monti M, Santulli C, Maniruzzaman M, Foresti ML, et al. Okra (Abelmoschus esculentus) Fibre Based PLA Composites: Mechanical Behaviour and Biodegradation. Journal of Polymers and the Environment. 2013;21(3):726-737. Available from: https://dx.doi.org/10.1007/s10924-0130571-5.

26) Zhang H, Liu T, Wang Y, feng Liu H, tao Zhang J, shuang Wu Y, et al. Laparoscopic left hepatectomy in swine: a safe and feasible technique. Journal of Veterinary Science. 2014;15. Available from: https://dx.doi.org/10.4142/jvs.2014.15.3.417.

27) Yilmaz ND, Koyundereli CG, Yilmaz K, Thakur VK, Thakur MK. Natural polysaccharides as pharmaceutical excipients. In: and others, editor. Handbook of Polymers for Pharmaceutical Technologies;vol. 3. Wiley Scrivener. 2015;p. 483-516.

28) Cook J, Gordon. Handbook of Textile Fibres. and others, editor;Woodhead Publishing Limited. 1984. 